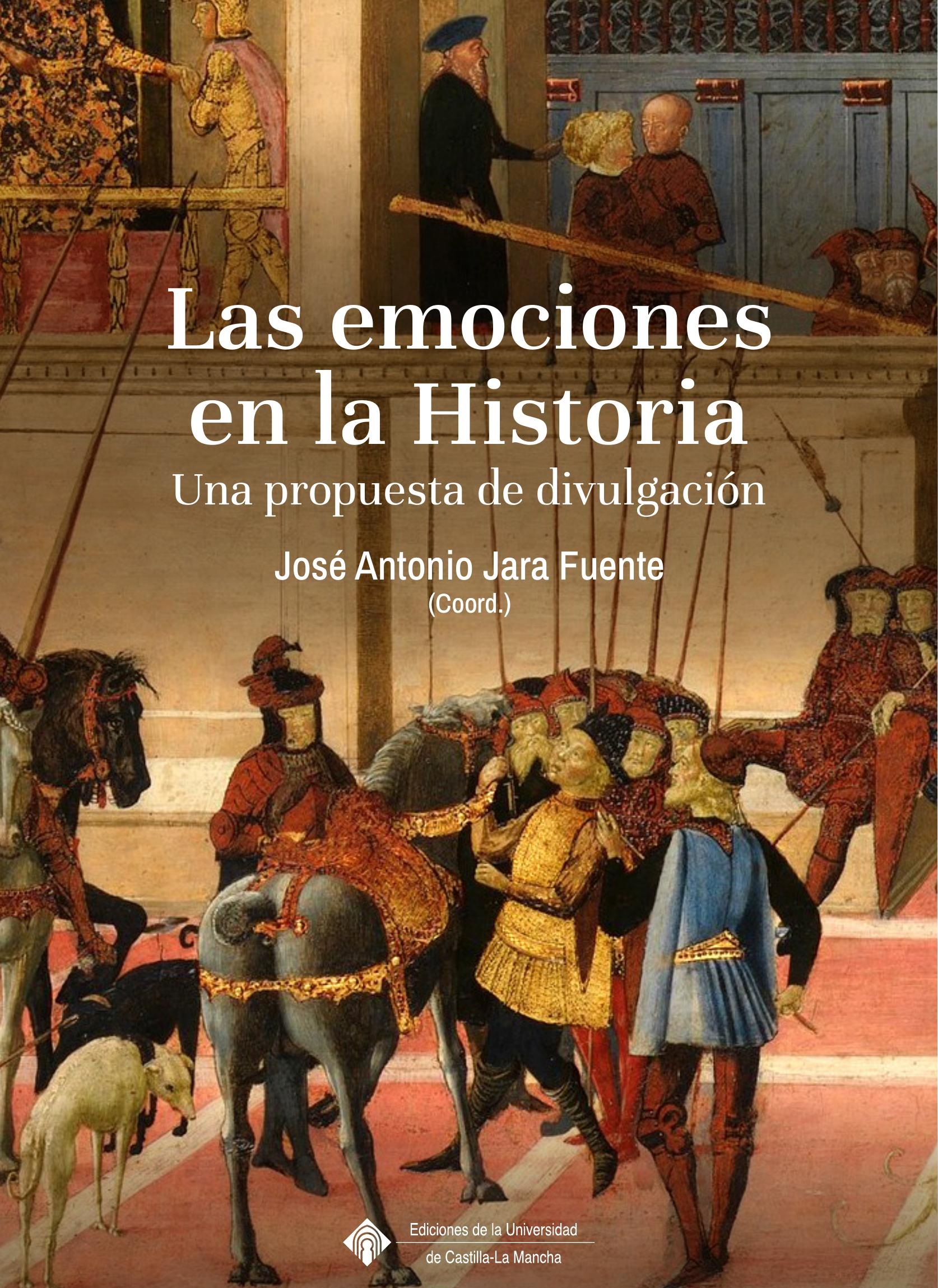





\section{Las emociones en la historia \\ Una propuesta de divulgación}





\title{
Las emociones en la historia Una propuesta de divulgación
}

\author{
José Antonio Jara Fuente
}

Coordinador

Ediciones de la Universidad

de Castilla-La Mancha

Cuenca, 2020 


\section{COMITÉ CIENTÍFICO:}

Dra. Irene González González, Universidad de Castilla-La Mancha

Dr. Juan Francisco Ruiz López, Universidad de Castilla-La Mancha

Dr. Miguel Ángel Valero Tevar, Universidad de Castilla-La Mancha

(C) de los textos: sus autores

(C) de la edición: Universidad de Castilla-La Mancha

Edita: Ediciones de la Universidad de Castilla-La Mancha

Colección DIVULGATIO n. ${ }^{\circ}$

Imagen de cubierta: Scenes from the Story of the Argonauts (ca. 1465). Jacopo del Sellaio. Metmuseum

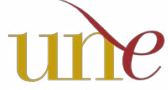

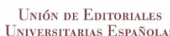

Esta editorial es miembro de la UNE, lo que garantiza la difusión y comercialización de sus publicaciones a nivel nacional e internacional

ISBN: 978-84-9044-410-8

DOI: http://doi.org/10.18239/divulga_2020.05.00

Composición: Compobell

Hecho en España (U.E.) - Made in Spain (U.E.)

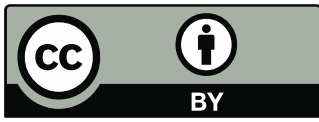

Esta obra se encuentra bajo una licencia internacional Creative Commons CC BY 4.0.

Cualquier forma de reproducción, distribución, comunicación pública o transformación de esta obra no incluida en la licencia Cretative Commons CC BY 4.0 solo puede ser realizada con la autorización expresa de los titulares, salvo excepción prevista por la ley. Puede Vd. acceder al texto completo de la licencia en este enlace: https://creativecommons.org/licenses/ by/4.0/deed.es

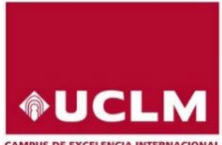

Vicerrectorado

de Cultura, Deporte

y Extensión Universitaria

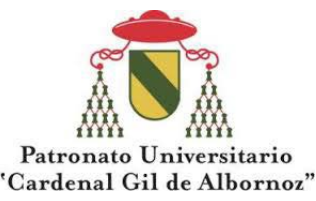

Proyecto de investigación CIUdAd y nOBLEZa EN EL TRÁNsITO a LA MODERNIDAD: AUTORITARISMO REGIO, PACTISMO Y CONFLICTIVIDAD POLÍTICA. CASTILLA, DE ISABEL I A LAS COMUNIDADES (REF. HAR2OI 7-83542-P, MICIN/AEI/FEDER 20I8-202I) 


\section{Índice}

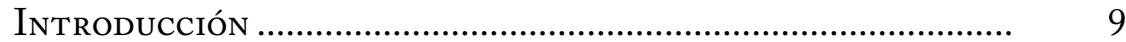

José Antonio Jara Fuente

EMOCIONES POLÍTICAS: UN ESTADO DE LA CUESTIÓN (CON ESPECial RefERencia A la EdAd Media)

José Antonio Jara Fuente

Sit Tibi TerRa LeVIS: LAS emociones en LAS ePigrafías fUneraRIAS ROMANAS

Lucía Arbeo Cuesta

Comunidades EN CONFLICTO: EXPRESANDO LAS EMOCIONES políticas en el espacio urbano. Flandes y Castilla en la Baja Edad MEdia

Beatriz Saiz Artiaga

En el nombre de Dios. Miedo, aVersión e ira en los proceSOS INQUISITORIALES

Alicia Caballero Salamanca

EMOCIONES CONTENIDAS EN LA CASA DESDE FINALES

del Antiguo Régimen

Carmen Hernández López

EL SIGLO DE LAS REVOLUCIONES: EMOCIONES Y POLÍTICA EN EL SIGLO XIX.

Andrea Villegas Marchante 
Emociones y sentimientos: Porrajmos, el holocausto

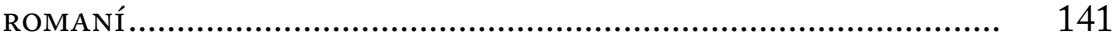

Isabel Martinez Bonilla

Miedo, represión, Guerra Civil y dictadura franquista .... 167 Sergio Nieves Chaves 


\title{
Miedo, represión, Guerra Civil y dictadura franquista
}

\author{
Sergio Nieves Chaves* \\ Universidad de Castilla-La Mancha \\ Sergio.NievesChaves@uclm.es \\ http://doi.org/10.18239/divulga_2020.05.09
}

\begin{abstract}
Resumen: Contextos bélicos o autoritarios como la Guerra Civil española o la dictadura franquista son escenarios clave para estudiar emociones como el miedo y ofrecer una perspectiva diferente del conflicto. El objetivo de las siguientes páginas es realizar una sucinta aproximación a la represión desencadenada en ambos momentos desde la óptica del miedo; un miedo que tuvo varias funciones y no fue homogéneo, sino multiforme y con muchas caras, fruto del amplio abanico de prácticas violentas, actores, medios de representación y contextos.
\end{abstract}

Palabras clave: Guerra Civil española; dictadura franquista; represión; miedo.

\section{Fear, repression, Civil War and the Franco dictatorship}

Abstract: War or authoritarian contexts such as the Spanish Civil War and the Franco dictatorship are key scenarios to study emotions like fear and offer a different perspective of the conflict. The aim of this paper is to make a succinct approach to the repression unleashed in both moments from the perspective of fear; a fear that had several functions and was not homogeneous, but multiform and with many faces, the result of the wide range of violent practices, actors, means of representation and contexts.

Keywords: Spanish Civil War; Franco Dictatorship; Repression; Fear.

* https://orcid.org/0000-0001-8596-7218 


\section{INTRODUCCIÓN}

La Guerra Civil y la dictadura franquista constituyen, sin duda, los acontecimientos que marcaron el siglo XX español. De manera particular, las prácticas violentas y represivas que tuvieron lugar en el desarrollo de la contienda y los años posteriores a su finalización han permeabilizado y marcado la memoria de sus protagonistas. Quienes vivieron aquel pasado traumático, de manera más o menos directa, experimentaron profundas y variopintas emociones, sentimientos y estados afectivos. El fallido golpe militar del i8 de julio de 1936 contra el gobierno legítimo de la Segunda República ocasionó una profunda fractura en todos los ámbitos y niveles. La rebelión de una parte del ejército y la puesta en escena de las armas ${ }^{\mathrm{I}}$ (como vehículo para la resolución de conflictos y la regulación de las normas de consenso) abrió un proceso de violencia del que hombres, mujeres, organismos e instituciones dejaron constancia en ambas retaguardias. Proceso que siguió en los años inmediatamente siguientes a 1939 por parte de quienes habían salido victoriosos de aquella tragedia.

La sistemática e indiscriminada maquinaria represiva franquista añadió más leña al fuego. La constante humillación y el férreo control social al que fueron sometidos los vencidos hicieron que las heridas emocionales y psicológicas de la guerra se agravasen ${ }^{2}$. Incluso, en aquellos que se exiliaron, pues también experimentaron fuertes reveses afectivos que les condujeron al sufrimiento y el refugio emocional y a la construcción de comunidades emocionales con las que «desahogar sus emociones, pero también ubicar sus vidas, sus experiencias comunes y sus expectativas» ${ }^{3}$. Miedo, melancolía, angustia, injusticia o impotencia solo fueron algunas de las emociones que estuvieron ligadas de manera estrecha a la (fatídica) experiencia biológica de la represión. Sin temor a equivocarse, por tanto, las guerras o los regímenes totalitarios (como los aquí citados) deben considerarse firmes acontecimientos capaces de producir u originar modelos conductuales, experienciales y emocionales de gran complejidad. Son fuentes generadoras de impresiones mayormente negativas (odio, dolor, trauma, muerte, etc.), pero también dejan un pequeño espacio para el florecimiento de emociones con una carga más positiva (como la generosidad, la compasión, la honestidad, la humildad).

La guerra española es un tema sumamente trabajado por los historiadores e investigadores de otras disciplinas, así como desde fuentes, enfoques y planteamientos metodológicos varios. Y, en particular, la cuestión de la represión

1 CASANOVA, 1999: 62-63.

2 RUIZ VARGAS, 2010: 140.

3 RODRÍGUEZ-LÓPEZ y VENTURA HERRANZ, 2014: 113. 
ha sido la que mayor atención ha recibido, no solo por la significación y el impacto que produjo en quienes la padecieron, ejercieron o fueron espectadores, sino también por el interés social y el intenso uso público de que ha sido objeto. Pese al abrumador interés historiográfico ${ }^{4}$, su exploración no se ha agotado y muestra de ello es el hecho de que no se haya abordado desde la perspectiva emocional. Con todo, siendo una tarea pendiente su abordaje desde la historia de las emociones, lo que se propone en las siguientes páginas es una sucinta aproximación a la represión durante la Guerra Civil desde la óptica del miedo; un miedo que no fue homogéneo, sino multiforme y con muchas caras, fruto del amplio abanico de prácticas violentas, actores, medios de representación y contextos.

\section{ALGUNAS CONSIDERACIONES TEÓRICAS SOBRE EL MIEDO}

El miedo, dentro de la historia de las emociones, es considerado como una emoción primaria, primitiva y perdurable que podría definirse (con miras al contexto en que nos movemos) como un «sentimiento de malestar suscitado por la presencia y conocimiento de un peligro al que se atribuye una influencia perjudicial a nuestros intereses» ${ }^{5}$. Los enfoques teóricos sobre el mismo son múltiples. Así, desde la fisiología, es entendido como ese mecanismo innato cuya reacción física se traduce en varias señales corporales más o menos inmediatas (como, por ejemplo, la alteración del ritmo cardiaco o el aumento de la presión arterial). Por su parte, la sociología y los estudios culturales (además de asumir los fundamentos biológicos) lo entienden como un constructo individual o colectivo en el que intervienen agentes sociales y culturales de diversa índole, por lo que el hecho de aprender o dejar de temer entes, objetos, personas o contextos varía en función de las circunstancias históricas de cada momento ${ }^{6}$.

El miedo recubre, a su vez, sentidos muy distintos: la angustia de la espera, la desorientación espacial, la visión anunciadora de la muerte, el sobrecogimiento al contemplar cuerpos muertos o mutilados... El miedo puede ser individual, intransferible, pero su dimensión social no tiene por qué acabar ahí. Esta se ensancha en el momento en el que un determinado colectivo o grupo comparte la misma experiencia (un buen botón de muestra serían los combatientes en las trincheras)7.

4 VIÑAS y BLANCO, 2017.

5 GONZǺLEZ CALLEJA, 2012: 14.

6 BOURKE, 2005: 74-75.

7 BERTHIER y SÁNCHEZ BIOSCA, 2012: 1. 
En perspectiva histórica, el miedo en la guerra ha ido ganando nuevas coordenadas, presentando distintas variantes. A partir de la Primera Guerra Mundial, el carácter poliédrico y los diferentes semblantes que tomaron las guerras modificaron la representación y función del miedo. En este sentido, la guerra civil española, como encrucijada de diferentes "guerras de cultura»" y escenario internacional de la lucha entre democracia, comunismo y fascismo, podría considerarse como uno de los primeros marcos donde los actos represivos y la deshumanización del enemigo adquirieron formas diversas. Modalidades de profundas raíces e índole varia que, a su vez, generaron experiencias psicológicas y emocionales desconocidas para la gran mayoría9 ${ }^{9}$ La «limpieza de la retaguardia», los atropellos contra civiles, los bombardeos indiscriminados, entre otros, fueron nuevos síntomas del cambio represivo y el modo de hacer la guerra, pero también nítidas evidencias del trauma emocional que dejaría la contienda.

La emoción del miedo, incluso, fue mucho más allá. El fenómeno represivo no solo estuvo compuesto de secuelas y actos eminentemente físicos, sino también psicológicos, porque las gentes imaginaron temerosamente aquello que podía llegar a pasarles. De este modo, el miedo se instrumentalizó y cumplió distintas funciones, desde efecto disuasorio a elemento básico de la amenaza. Como igualmente diferentes fueron las formas de representación y las estrategias a través de las cuales se apeló, promovió y extendió. En ese contexto de «cultura de guerra», dominada por el empleo brutal y desmesurado de la violencia y la deshumanización del enemigo, es donde hay que insertar y analizar la presencia del miedo ${ }^{\mathrm{I}}$.

\section{EL MIEDO EN LAS RETAGUARDIAS REPUBLICANAYSUBLE- VADA DURANTE LA GUERRA CIVIL}

En contextos de violencia, polarización y fragilidad gubernamental como el de los primeros meses de la Guerra Civil, rumores e informaciones faltas de veracidad ocasionaron actos más o menos espontáneos caracterizados por la acción colectiva estandarte del binomio miedo-violencia dirigido contra un enemigo con rostro $y$, a menudo, indefenso. El riesgo inmediato y el desasosiego presentes en este tipo de actos hicieron que el miedo se entremezclara con otras emociones como la venganza o el odio. Atendiendo a estas premisas, un ejemplo sumamente revelador de cómo la violencia

8 GRAHAM, 2006: 12.

9 BERTHIER y SÁNCHEZ BIOSCA, 2012: 2.

10 GONZÁLEZ CALLEJA, 2008. 
viene impulsada por la amenaza y el temor contrarrevolucionario se sitúa en la noche del 22 agosto de 1936 en Madrid, con el asalto a la cárcel Modelo. En medio del desenfrenado y funesto avance de las tropas sublevadas, que pocos días antes de los sucesos había dejado a su paso por Badajoz un reguero enorme de sangre; de los bombardeos rebeldes sobre la ciudad en los días inmediatamente anteriores; de las indirectas del general Mola acerca de la existencia de una "Quinta Columna» en su interior; de la movilización miliciana hacia el frente para salvaguardar la ciudad; y de la falta de capacidad política para actuar por parte del gobierno de José Giral, los presos políticos se amotinaron en el penal con el fin de escapar. Estas noticias hicieron que un grupo de milicianos anarquistas llegara al lugar para tomar las riendas de la situación, que acabó saldándose con la ejecución ante un tribunal revolucionario de una treintena de personalidades políticas y militares de renombre. Este acontecimiento muestra, fundamentalmente, dos asuntos: en primer lugar, que ante situaciones de desconcierto y confusión las directrices gubernamentales tienen poco peso debido al poder acumulado por otros organismos o grupos (en este caso, las milicias); en segundo lugar, como consecuencia de lo anterior, que la represión cometida por el enemigo es un pretexto para actuar contra sus correligionarios políticos, convirtiendo la violencia en un hecho de carácter preventivo estimulado por el miedo.

La canalización del miedo a través de la violencia contra reclusos también fue algo que tuvo lugar en la «zona azul». Fue el caso de Ávila, también a finales de agosto del mismo año. El bombardeo de la aviación republicana de la ciudad condujo a un buen grupo vecinal a que se tomaran represalias. Sus miradas se dirigieron a un blanco concreto, los presos antifascistas de la cárcel provincial, y sus peticiones se vieron correspondidas con el fusilamiento de más de una decena. Esta vez, los militares rebeldes fueron quienes recogieron las demandas de miedo producto del ataque aéreo y las transformaron en un acto represivo, a todas luces, vengativo y de marcado tinte político.

Entre las funciones que jugó el miedo en vinculación con la represión, una de ellas fue ejemplificadora. El golpe militar puso sobre la mesa las armas y la violencia como vía para la resolución de conflictos. En el caso de la retaguardia republicana, además, provocó el desmoronamiento del Estado central (y, por tanto, de sus medios coercitivos y su aparato judicial) y la apertura de un proceso revolucionario donde variopintos micropoderes llenaron y disputaron el vacío de poder dejado tras la derrota de los insurgentes. Durante los primeros meses de «terror caliente», coincidentes con los niveles represivos más altos de todo el conflicto, checas, comités de guerra de las Columnas, comités de Salud Pública, grupos de investigación, entre otros nuevos organismos, 
emplearon la violencia y el miedo como instrumento para el control político de la retaguardia, la eliminación de los representantes del viejo orden social y la consecución de un espacio en el propio proceso revolucionario. Entre los modos y mecanismos de actuación de los nuevos actores la norma general fue reprimir desde la ilegalidad institucional, siendo la práctica de justicia expeditiva más extendida el paseo.

No obstante, en los primeros días de conflicto, tuvo lugar una modalidad represiva, si bien excepcional, de gran carga simbólica y emocional: los juicios en las plazas de los pueblos o en los balcones del Ayuntamiento. En un momento de gran confusión, donde el ataque rebelde podía tener sus efectos y la gente desconfiaba del aparato judicial institucional, derechistas y simpatizantes del «Alzamiento» fueron detenidos y «juzgados» en acto público a plena luz del día ${ }^{\text {II }}$. La presentación del enemigo al «pueblo» y la competencia de este para decidir qué hacer con él fue una estrategia manifiesta de que, ahora, el poder y el ejercicio de la justicia, estaban en nuevas manos. Pero, más allá de ello, esta «justicia por consenso» ${ }^{\mathrm{I}^{2}}$ (no legal, pero «justa» a ojos de muchos vecinos) tuvo, entre otros fines, generar una lección; una lección donde el miedo fue un componente esencial. La propia exhibición del capturado y su condena se hizo para persuadir al resto, para «meter el miedo en el cuerpo» a aquellos que mostraran actitudes análogas y compartieran el credo de los sublevados.

Por otra parte, el miedo se manifestó y dejó sentir como mecanismo de defensa natural ante una tesitura tan intensa, como, por ejemplo, la extracción y ejecución de detenidos. En este sentido, resulta sintomática la declaración contenida en un Procedimiento Sumarísimo de Urgencia de 1939 por un vecino de la localidad conquense de Villamayor de Santiago cuando se le preguntaba por los asesinatos cometidos en ella la noche del 22 de agosto de 1936. De acuerdo con su declaración, dicha noche, le invitaron a ir a la Plaza del pueblo, donde le propusieron matar al sacristán, a lo cual se negó. Trataron de emborracharlo con anís, sin lograrlo, mientras que al resto les hizo efecto hasta el punto de ponerse furiosos:

«momento en el que comenzó la preparación para los crímenes. Que al ver el dicente esta actitud intentó marchar a su casa con el pretexto de coger el llavín de la misma, cosa que no consiguió (...) que la madre del dicente le llamó desde un balcón de casa de su abuela, obedeciendo rápidamente

11 LEDESMA VERA, 2003: 140.

12 ALBA, 1990: 226. 
a la llamada (...) y cuando se dirigía hacia ella le dijeron que si andaba un paso más lo matarían allí mismo».

Le advirtieron que «si algo le preguntaba algún detenido les contestara que iban a Tarancón, que de no hacerlo así lo matarían, y si intentaban huir después haría igualmente con todos los que se encontraban detenidos». Y, una vez en el cementerio y con dos víctimas en el suelo, le obligaron a coger «a una de ellas por el tobillo de la pierna izquierda y notó como aún tenía vida, por lo que la soltó enseguida (...) y se disparó nuevamente sobre ella»r³.

Como puede comprobarse, el miedo se hace patente a lo largo de la declaración de un elemento cuyo constante estado emocional de angustia y temor se debe a que era considerado por el comité local como un elemento de ideas «facciosas». Bajo esta premisa, el miedo del dicente al negarse a cometer cualquier crimen y al estar presente en las ejecuciones viene dado por la incómoda situación de presión a la que se le somete; al hecho de tener que matar a vecinos (conocidos y amigos) correligionarios ideológicos. Por ello, ante la mínima oportunidad que se le presenta pretende huir de aquel ambiente para evitar se le relacione con tales actos. Además, desde la perspectiva de quienes cometieron los crímenes, la embarazosa situación a la que someten al declarante tiene, de nuevo, un fin aleccionador: estás con nosotros o con ellos. Incluso, podría interpretarse que los actores de la violencia también sintieron miedo (o, al menos, una mínima angustia y resentimiento) respecto al hecho de empuñar el arma. Por ello, intentan «engañar» a esa sensación a través del alcohol. Este caso, una vez más, ejemplifica perfectamente la conexión entre miedo y represión política y psicológica.

En la retaguardia insurgente, el miedo también fue una emoción-respuesta. Situaciones descabelladas como la masacre de Badajoz provocó en los espectadores de aquella carnicería un pánico extremo y desvanecedor, tal y como le sucedió a María de Luz Mejías Correa, miliciana de las Juventudes Socialistas Unificadas, quien comenta en sus memorias:

«El montón de muertos que fusilaron ahí llegaba a la ventana del Ayuntamiento de Badajoz. La sangre corría por la calle del Obispo abajo, por la calle Magdalena y por la calle Socorro (...) como agua de lluvia (...) Fusilaron allí, fusilaban en la Plaza de toros y en las paredes del cementerio (...) Cargaban los muertos en camiones y carros, los llevaban al cementerio y los echaban a las fosas comunes. Así fue como pasó esto... $)^{\text {r4 }}$.

13 ARCHIVO GENERAL E HISTÓRICO DE DEFENSA, Madrid, Sumario 281, Legajo: 2922.

14 MEJÍAS CORREA, 2006: 63. 
Aquel reguero de sangre que llenó las calles de la ciudad extremeña repercutió de manera negativa en esta miliciana. Aterrada por lo que habían sido capaces de hacer las tropas dirigidas por el coronel Yagüe y paralizada por la fatalidad de quien no se espera tales extremos, su testimonio es un claro ejemplo de cómo, desde primera hora, la represión franquista tuvo como pilares fundacionales la impresión del miedo como medio de sometimiento.

En otro orden de cosas, más allá de la detención y fusilamiento de derechistas y «facciosos» en territorio republicano y de izquierdistas y antifascistas en el sublevado como método represivo más extendido, otras formas represivas tuvieron cabida a lo largo y ancho del país, como la laboral, la moral, la simbólica o la sexual. Los saqueos, las incautaciones, las depuraciones, la destrucción de imágenes religiosas o la agresión sexual fueron actos donde el miedo fue un ingrediente más del estado emocional de sus protagonistas. Pero, al mismo tiempo, en muchas de estas acciones el miedo se convirtió en una emoción política. En este sentido, la violencia sexual como castigo contra las mujeres, independientemente de los ideales que defendieron, alumbra tal consideración.

El caso de Piedad Suárez de Figueroa Moya, vecina de la localidad toledana de Villanueva de Alcardete, es un buen ejemplo. Aunque la violación formó parte de la maquinaria sancionadora rebelde y se dieron multitud de casos, la zona republicana (como la que se acaba de indicar) también fue escenario de ello. Piedad, vista por sus victimarios como representante del más puro y activo catolicismo y de la clase acomodada, fue violada y asesinada por varios miembros de los Comités de su pueblo de origen y del vecino Villamayor de Santiago, en septiembre de 1936. Su violación y asesinato puede interpretarse como una estrategia de guerra, en el sentido de conquista del territorio. Pero, si se profundiza en esa perspectiva simbólico-emocional, esta violación podría decirse que formó parte del ideario político de la revolución que situó a la mujer en un objeto de castigo en sí mismo, pues ella era parte del viejo orden social que se quería destruir ${ }^{15}$. El miedo, la angustia y el pánico que debió tener y sentir la víctima no fue solo una emoción indudable de aquel acto. Desde la óptica de sus verdugos, esta política del miedo tuvo como objetivo llamar la atención del contrario, así como limitar cualquier capacidad de acción del enemigo emboscado en la retaguardia. $\mathrm{O}$, si se prefiere, el miedo operó con el fin de preservar el statu quo.

15 CASES SOLA, 2014: 77. 


\section{A MODO DE CONCLUSIÓN: DEL MIEDO DE GUERRA AL TERROR FRANQUISTA DE POSGUERRA}

El empleo metódico y sistemático de la violencia no solo convirtió a esta última en instrumento de control político y social, sino que, además, llevó al miedo al máximo de sus límites. Las acciones violentas llevadas a cabo de manera premeditada, repetida e intimidatoria hicieron que el miedo diera paso al terror. El terror entendido, por tanto, como estrategia de intimidación, amenaza y aplicación regular de modalidades violentas con la que amedrantar, influir y someter a la población. En este sentido, los primeros 6 meses de la guerra conocieron una violencia indiscriminada, a uno y otro lado de la vanguardia. Si bien esta realidad fue común en ambas retaguardias, la violencia de los sublevados (y, por tanto, su dominio del miedo) adquirió connotaciones mucho más drásticas, más cercanas al modelo de «terror unilateral y paralizador $\aleph^{16}$. Desde el primer momento, la cultura política preponderante en los diferentes sectores identificados con los militares rebeldes contempló la violencia, además de como instrumento cohesionador, «como un valor en sí mismo que orientaba la conducta moral y política (...) Una estrategia de aplicación del terror para anular políticamente a los vencidos en la guerra que se mantendría activa hasta los últimos estertores de la dictadura $»^{17}$.

La utilización del miedo como vehículo de sumisión y sometimiento fue empleado por la dictadura franquista con un doble objetivo: por un lado, para amedrentar, humillar y condenar al silencio y a la marginación emocional a quienes habían perdido la guerra; y, por otro, para la construcción de la «Nueva España» monolítica. El franquismo, a lo largo de cuatro décadas, diseño un sistema coercitivo estructural que evolucionó en objetivos, métodos e intensidad. La violencia fue el instrumento predilecto de control de la «desviación social», el garante del consenso y la cultura franquista. Pero, también, supuso una técnica disuasoria contra el conjunto de la sociedad (y, de manera particular, contra la oposición política), a fin de crear y extender el miedo. Continuamente, la dictadura apeló a la violencia y al exterminio del «rojo» mediante una socialización del miedo que, incluso, llegó a negar la condición de humano a su enemigo ${ }^{18}$. Con todo, la dictadura franquista podría considerarse un régimen emocional caracterizado por una serie base de rituales y prácticas afectivas para su correcta estabilidad y devenir ${ }^{19}$.

16 RODRIGO, 2003256.

17 GONZÁLEZ CALLEJA, 48 (2013): 77.

18 ORTIZ HERAS, 2013: 25-43.

19 REDDY, 2001: 129. 
Esa cultura del miedo (que, como se ha dicho, se manifestó a través de una represión poliédrica y mutante) como arma intimidatoria brilla de manera sobresaliente en el legado literario de los presos de las cárceles y campos de concentración franquistas. Las memorias de Andrés Iniesta López, hijo del alcalde republicano en guerra del pequeño pueblo conquense de Uclés, vienen a simbolizar ese paradigma de resistencia al miedo y la opresión como otros tantos escritos similares. Antes de ser encarcelado en el monasterio convertido en prisión de dicho pueblo con apenas I7 años, cuenta que llevado al campo de concentración instalado en el teatro de Tarancón junto a otros 5 compañeros:

«esa noche fue espantosa. Con cada relevo de guardia nos parecía que venían a por nosotros. Los dos más metidos en años lloraban. El miedo a la muerte se apoderó de ellos, al tiempo que se quejaban de las fuertes palizas recibidas. Las horas que más temimos fueron las de la madrugada, pensamos que sería nuestro final $\aleph^{20}$.

La inseguridad provocada por desconocer su desenlace; la ansiedad emergida al ignorar qué sucederá con sus familias (a las que probablemente, pensarían, nunca verán más); y el miedo y temor a acabar ante un piquete de ejecución fueron estados emocionales sintomáticos de los presos de Franco. Como también fueron reveladores el agotamiento físico y emocional de haber luchado por la causa republicana en testimonios de mujeres encarceladas. Por su doble condición de «roja» $\mathrm{y}$ «mujer», el régimen les reservó una particular represión ${ }^{21}$. El siguiente testimonio de Petra Cuevas nos sitúa en el escenario emocional de lo que supuso la entrada a la cárcel:

«Al finalizar la guerra mi problema fue el de todos los españoles que luchamos al lado de la República. Andar a salto de mata en aquellos primeros días hasta caer en Gobernación. Lo que allí se pasaba es inenarrable: las mayores torturas, las mayores humillaciones que un ser humano puede aguantar (...) De Gobernación a la comisaría de Fomento (...) Ahí nadie puede imaginar lo que pasaba. Eso era un infierno. Estábamos en habitaciones muy pequeñas con ventanas a un patio interior. A todo el que pegaban, a todo el que interrogaban, oías los gritos, oías los que les hacían. No era lo que te hacían a ti, es que oías lo que les hacían a los demás y era enloquecedor. Para más humillación nos hacían cantar el Cara al sol todos los días, hacer el saludo fascista (...) ${\aleph^{22}}^{2}$.

20 INIESTA LÓPEZ, 2006: 29.

21 EGIDO LEÓN, 2017: 8.

22 CUEVAS GUTIÉRREZ, 2004: 361-363. 
De estas líneas se desprende cómo el miedo se fue fraguando desde el momento que pisó Gobernación. La banda sonora de los gritos de compañeros hacía que el miedo al «qué me harán» fuera cada vez más grande y que acabara perdiendo la razón. Un miedo agravado por la humillación y el adoctrinamiento que suponía la obligación de efectuar el repertorio simbólico de los vencedores. Y, además, un golpe psicológico y simbólico que nos habla del férreo dominio y opresión que se ejerció contra los vencidos.

Los presos y las presas de la dictadura franquista formaron una comunidad emocional ${ }^{23}$, no solo por su condición de reclusos, sino también por la faceta de «escritores» y el legado literario que ha llegado hasta nuestros días. Los diarios, las memorias o las cartas, además de dar a conocer las difíciles circunstancias vitales y las particularidades represivas dentro de las prisiones, deben interpretarse como un intento con el que sobreponer el dolor y el trauma, como un modo de resistencia frente al olvido y como una manifestación surgida de toda una comunidad emocional.

Podrían enumerarse multitud de ejemplos más cuyos análisis, a su vez, con toda probabilidad, ofrecerían nuevas miradas e interpretaciones sobre el miedo y su conexión en contextos represivos como la Guerra Civil o la dictadura franquista. Siendo una tarea pendiente un estudio más profundo de las emociones y, entre ellas, el miedo, para estas etapas traumáticas de la historia de España, las anteriores líneas han pretendido esbozar algunas consideraciones al respecto. El miedo constituyó una emoción indisoluble y estrechamente ligada al fenómeno violento que cumplió varias funciones en la medida de quienes fueron los protagonistas y la coyuntura y circunstancias en que se emitieron las prácticas. Así, se puede establecer que el miedo fue un mecanismo de cohesión política o un vehículo con el que legitimar decisiones.

\section{BIBLIOGRAFÍA}

Alba, Víctor, «De los Tribunales Populares al Tribunal Especial», en Ministerio de Cultura, Justicia en guerra. Jornadas sobre la administración de justicia durante la guerra civil española: instituciones y fuentes documentales Madrid, Ministerio de Cultura, Dirección General de Bellas Artes y Archivos, 1990; 223-238.

23 Entendida en términos de su creadora, Bárbara Rosenwein, esto es, «grupo vinculado por un "sistema de sentimientos" mediante el que definen las emociones propias y ajenas, los lazos afectivos que los unen y los modos de expresión sentimental que alientan, deploran, recuperan o arrinconan». Citado en BARRERA y SIERRA, 2020: 126 . 
Barrera, Begoña y Sierra, María, «Historia de las emociones: ¿qué cuentan los afectos del pasado?», Historia y Memoria [En línea], Número Especial (2020): https:// doi.org/Io.19053/20275137.nespecial.2020.11583.

Berthier, Nancy y Sánchez Biosca, Vicente (eds.), Retóricas del miedo. Imágenes de la Guerra Civil española, Madrid, Casa de Velázquez, 2012.

Bourke, Joanna, Fear: A Cultural History, Londres, Virago, 2005.

Casanova, Julián, «Rebelión y Revolución», en Santos Juliá (coord.), Victimas de la Guerra Civil, Madrid, Temas de Hoy, 1999; 57-186.

Egido León, Ángeles (coord.), Cárceles de mujeres. La prisión femenina en la posguerra, Alcorcón: Sanz y Torres, 20I7.

Cases Sola, Adriana, «La violencia sexual en la retaguardia republicana durante la guerra civil española», Historia Actual Online, 34 (2014), pp. 69-80.

Cuevas Gutiérrez, Tomasa, Testimonio de mujeres en las cárceles franquistas, Huesca, Instituto de Estudios Aragoneses, 2004.

González Calleja, Eduardo, «La cultura de guerra como propuesta historiográfica: una reflexión general desde el contemporaneísmo español», Historia Social, 6I (2008), pp. 69-87.

González Calleja, Eduardo, «El poder del miedo. El temor y la intimidación como instrumentos de acción política», en Nancy Berthier y Vicente Sánchez-Biosca (eds.), Retóricas del Miedo: Imágenes de la Guerra Civil Española, Madrid, Casa de Velázquez, 20I2, pp. 13-28.

Gonzalez Calleja, Eduardo, «La construcción social y política del miedo en la primavera de I936", Bulletin d'Histoire Contemporaine de l'Espagne, 48 (20I3), pp. 6I-77.

Graham, Helen, Breve historia de la Guerra Civil, Madrid, Espasa Calpé, 2006.

Iniesta López, Andrés, El niño de la prisión, Madrid, Ediciones Siddharth Mehta, 2006.

Ledesma Vera, José Luis, Los días de llamas de la revolución: violencia y politica en la retaguardia republicana de Zaragoza durante la guerra civil, Zaragoza, Fernando el Católico, 2003.

Mejías Correa, María de la Luz, Así fue pasando el tiempo: memorias de una miliciana extremeña, Sevilla, Renacimiento, 2006.

Ortiz Heras, Manuel, La violencia politica en la dictadura franquista. La insoportable banalidad del mal, Albacete, Bomarzo, 20I3.

Reddy, William M., The Navigation of Feeling. A Framework for the History of Emotions , Cambrige, Cambridge University Press, $200 \mathrm{.}$ 
Rodrigo, Javier, «1936. Guerra de exterminio, genocidio, exclusión», Historia y Politica. Ideas, procesos y movimientos sociales [En línea], io (2003). Disponible en: https:// recyt.fecyt.es/index.php/Hyp/issue/view/249I [Consultado el I7 de octubre de 2020].

Rodríguez-López, Carolina y Ventura Herranz, Daniel, «De exilios y emociones», Cuadernos de Historia Contemporánea [en línea], 36 (2014). Disponible en: https:// doi.org/ro.5209/rev_CHCO.2014.v36.46684.

Ruiz Vargas, José María, «Trauma y memoria de la Guerra Civil y de la dictadura franquista», en Julio Aróstegui Sánchez y Sergio Gálvez Biesca (coords.), Generaciones y memoria de la represión franquista: un balance por los movimientos de la memoria, Valencia, Servicio de Publicaciones de la Universidad de Valencia, 2oro, pp. 139-180.

Viñas, Ángel y Blanco,Juan Andrés, La Guerra Civil española, una visión bibliográfica. Madrid, Marcial Pons, 20I7. 
